\title{
Assessment right atrial thrombus by real-time three dimensional transthoracic echocardiography in patient with dilated cardiomyopathy
}

\author{
Wenjuan Bai ${ }^{1}$, Hui Li ${ }^{1}$, Qing Zhang ${ }^{2}$ and Li Rao ${ }^{1 *}$
}

\begin{abstract}
We report a case of a 52-year-old patient with dilated cardiomyopathy who presented with worsening heart failure. Two-dimensional transthoracic echocardiography and real-time three dimensional transthoracic echocardiography showed severe dilated cardiac chambers, impaired ejection fraction and a mobile right atrial thrombus $2.6 \times 1.0$ $\mathrm{cm}$ in size, traversing the right atrial cavity during the whole cardiac cycle. After one week therapeutic anticoagulation, echocardiography confirmed no evidence of residual thrombus.
\end{abstract}

Keywords: Thrombus Dilated cardiomyopathy, Echocardiography

\section{Introduction}

Dilated cardiomyopathy (DCM) is a kind of malignant cardiac disorder, which affects 5 in 100,000 adults and 0.57 in 100,000 children [1,2]. It represents a poor longterm prognosis with the mortality rate is $70 \%$ to $80 \%$ at eight years for most patients who undergo heart failure [3]. Right heart thrombus presents higher mortality [4] with a risk of pulmonary embolization [5], which has been found in patients with DCM rarely. Echocardiography plays a pivotal role in the evaluation of DCM and intracardiac masses. To the best of our knowledge, this is the first case report using combination of two-dimensional echocardiography and real-time three dimensional echocardiography in the assessment of right atrial thrombus happened in DCM.

\section{Case presentation}

A 52-year-old man (body surface area: $1.3 \mathrm{~m}^{2}$ ) known to have dilated cardiomyopathy (DCM), was admitted for worsening heart failure (NYHA class IV). He presented with a 5-month history of cough, progressive dyspnoea, orthopnea and recurrent upper abdominal pain started

\footnotetext{
* Correspondence: Irlz1989@yahoo.com.cn

'Echo lab, Division of Cardiology Medicine, West China Hospital of Sichuan University, Chengdu, (610041), China

Full list of author information is available at the end of the article
}

from 2 months ago. On examination his vital signs were body temperature $37^{\circ} \mathrm{C}$, blood pressure $80 / 40 \mathrm{mmHg}$, respiratory rate 24 breaths per minute, and electrocardiogram showed atrial fibrillation with heart rate 50 beats per minute. Physical examination revealed the jugular venous distension, significant tender hepatomegaly and bilateral pitting edema at lower limbs. Laboratory tests showed elevated pro-NT brain natriuretic peptide of $22145 \mathrm{pg} / \mathrm{ml}$ (normal 0 to $227 \mathrm{pg} / \mathrm{ml}$ ) and unremarkable D-dimer. X-ray and computed tomography of the chest demonstrated consolidation of bilateral lower lobes with pleural effusion, while his venous Doppler of lower extremities was normal. Based on his clinical condition, echocardiography was immediately inserted. There were severe dilated cardiac chambers, especially enlargement of the left ventricle (LV) (58 $\mathrm{mm} / \mathrm{m} 2$ ) with spherical shape, decreased wall thickness, impaired ejection fraction $22 \%$ and severe mitral regurgitation on two-dimensional transthoracic echocardiography (2DTTE). Parasternal short axis and subxyphoid view (Figure 1) showed the mobile right atrial mass highly suspicious of a thrombus traversing the right atrial cavity during the cardiac cycle accompanying with free-floating small parts of the thrombi. Real-time three dimensional transthoracic echocardiography (RT3DTTE) was performed to further confirm the nature of 


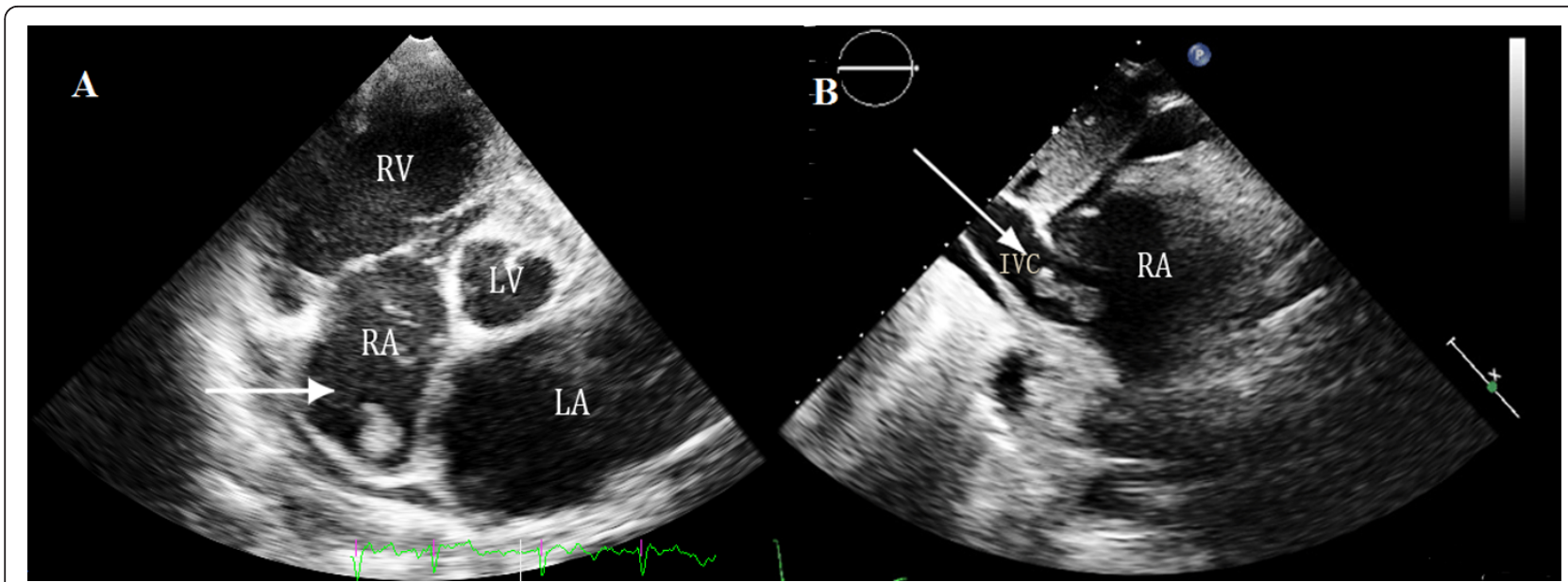

Figure 1 A mass of right atrium: A) Parasternal short axis view by 2D TTE, B) Subxyphoid view by $2 D$ TTE.

mass. It showed a highly mobile thrombus, irregular in contour, measured $2.6 \times 1.0 \mathrm{~cm}$ which floating around the orifice of inferior vena cava and protruding into the right atrial cavity (Figure 2). In addition, RT-3DTTE evaluated right ventricle (RV) systolic dysfunction with ejection fraction $15.7 \%$ (Figure 3 ). He was maintained on digoxin, spironolactone, furosemide, sotalol and dopamine. At the same time therapeutic anticoagulation was started with low-molecular-weight heparin and warfarin. The patient had an uneventful hospital course and one week follow-up echocardiography confirmed adequate removal of the thrombus (Figures $4 \mathrm{~A}$ and $4 \mathrm{~B}$ ).

\section{Discussion}

DCM is a multifactorial myocardial disease characterized by enlarged left or whole heart chambers and decreased heart function [6]. Symptoms of progressive heart failure are common in patients with dilated cardiomyopathy and endstage disease may predispose to

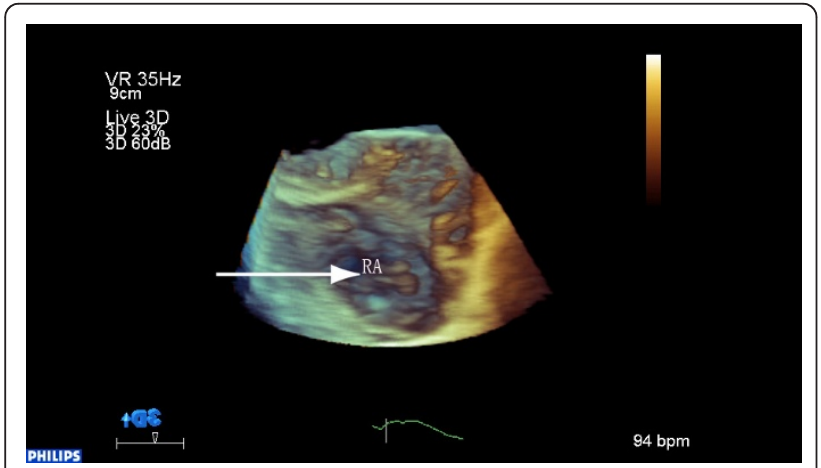

Figure 2 Mobile mass of right atrium: RT-3DTEE shows a $2.6 \times$ $1.0 \mathrm{~cm}$ homogeneously echogenic mobile mass which floating around the orifice of inferior vena cava and protruding into the right atrial cavity (arrow). arrhythmia associated with a high risk of thrombus formation which may lead to thromboembolic events [7]. Right heart thrombus happens about $4-18 \%$ cases with acute pulmonary embolism [8,9], while rare found in patients with DCM. They may develop within right heart because of atrial fibrillation, hypercoagulable state caused by disease or origin from peripheral venous clots due to bedridden condition that temporarily embolized to the right heart. This type of thrombus presents higher mortality [4] with a risk of potential fragmentation and causing massive pulmonary embolization [5].

Echocardiography is the most important non-invasive comprehensive method in clinical diagnosis of DCM as well as evaluating intracardiac masses or thrombi. In our report, the patient had a right atrial mass with the severity of both ventricle dysfunctions. Although

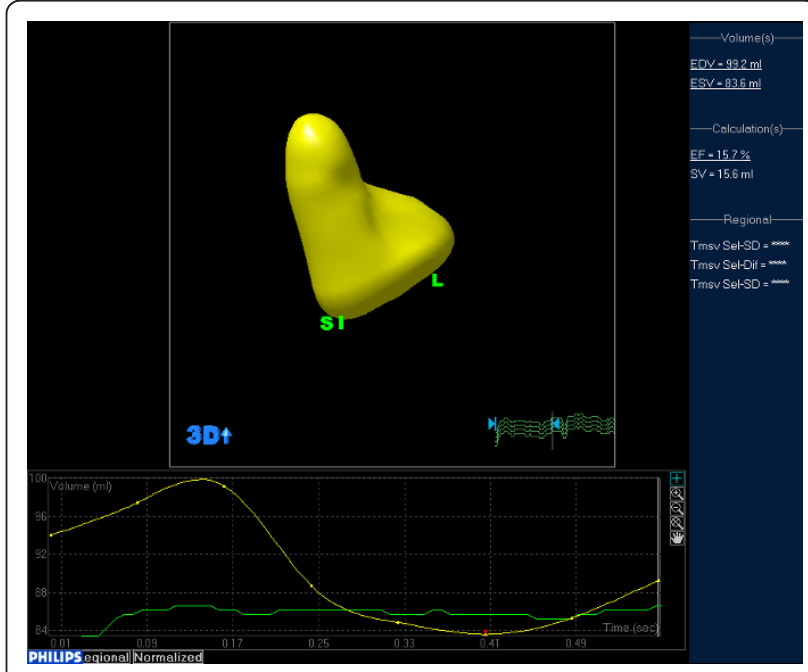

Figure 3 Right ventricular ejection fraction: RT-3DTEE measured right ventricular systolic dysfunction with an EF 15.7\%. 


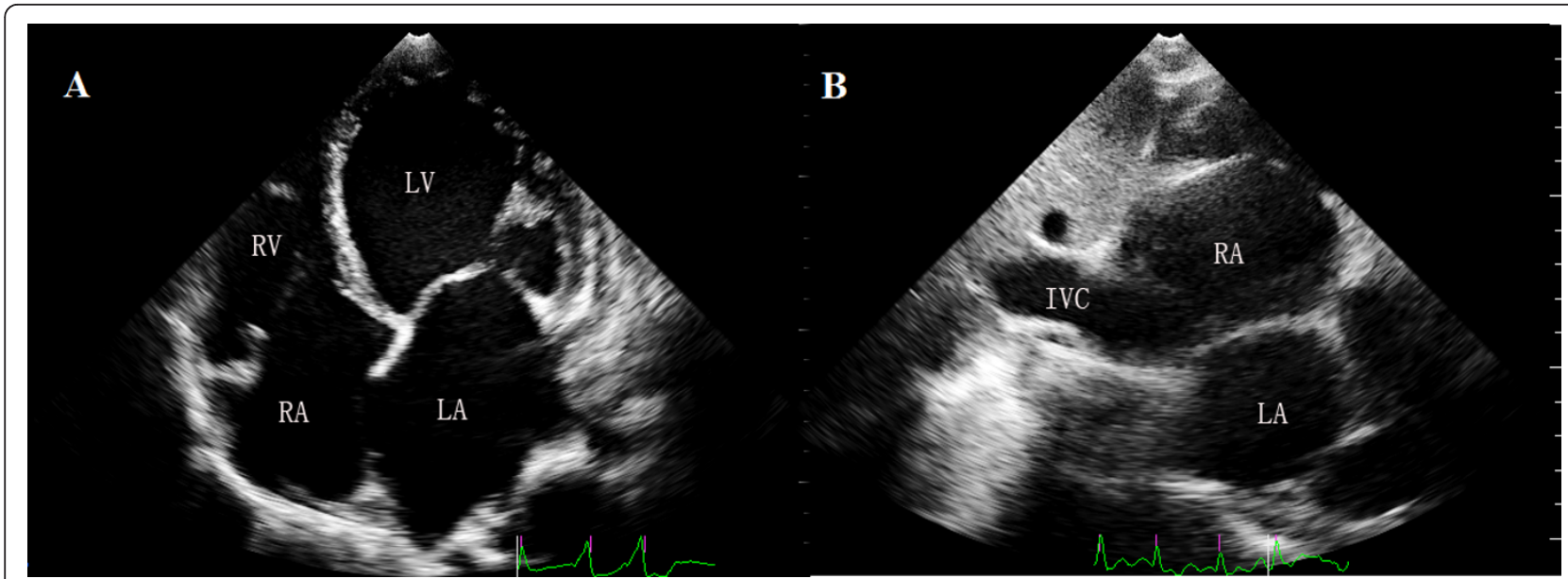

Figure 4 Follow up after 1 week anticoagulation: In A) apical 4-chamber view and B) subxyphoid view shows complete disappearance of the thrombi. $L V=$ left ventricle; $R A=$ right atrium; $R V=$ right ventricle, $L A=$ left atrium, IVC = inferior vena cava.

conventional 2DTTE can help to estimate cardiac structure, function and assess the hemodynamic effects, the RT-3DTTE adds valuable benefits as follows: (1) the RT-3DTTE can provide complete information of intracardiac masses[10] including size, shape, consistency, mobility and location that in relation to cardiac anatomical structures.(2) It allows us to differentiate the thrombus from other masses (e.g. cardiac tumors, vegetations) by revealing lobula, stalk, hyperechogenicity or hypoerechogenicity and spatial relationship with adjacent structures, which may help in demonstrating prognostic indications or the response to treatment.(3) In addition, RV dysfunction plays an important role in adverse outcome [11], RT-3DTTE provides a practical approach for quantified the RV function without relying on the geometric assumptions. (4) Patients with DCM usually have distorted LV shape. RT-3DTTE can quantify the LV function without long time breath holding and fully cooperative, also the result is more accurate even like as MRI technology [12]. In our presentation, the combination of 2DTTE and RT-3DTTE may facilitate the diagnosis in evaluating heart function and characterize the nature of thrombus better.

\section{Consent}

Written informed consent was obtained from the relative of the patient for publication of this case report and any accompanying images. A copy of the written consent is available for review by the Editor-in-Chief of this journal.

\section{Author details}

${ }^{1}$ Echo lab, Division of Cardiology Medicine, West China Hospital of Sichuan University, Chengdu, (610041), China. ${ }^{2}$ Division of Cardiology Medicine, West China Hospital of Sichuan University, Chengdu, (610041), China.

\section{Authors' contributions}

WB performed the echocardiography examination and drafted the manuscript. HL carried out the quantitative analysis. QZ performed the physical examination and collected the experimental materials. LR conceived of the report. All authors read and approved the final manuscript.

\section{Competing interests}

The authors declare that they have no competing interests.

Received: 30 January 2011 Accepted: 10 April 2011

Published: 10 April 2011

\section{References}

1. Dec GW, Fuster V: Idiopathic dilated cardiomyopathy. N Engl J Med 1994, 331:1564-1575.

2. Towbin JA, Lowe AM, Colan SD, Sleeper LA, Orav EJ, Clunie S, Messere J, Cox GF, Lurie PR, Hsu D, Canter C, Wilkinson JD, Lipshultz SE: Incidence, causes, and outcomes of dilated cardiomyopathy in children. JAMA 2006, 296:1867-1876.

3. Rosamond W, Flegal K, Friday G, Furie K, Go A, Greenlund K, Haase N, Ho M, Howard V, Kissela B, Kittner S, Lloyd-Jones D, McDermott M, Meigs J, Moy C, Nichol G, O'Donnell CJ, Roger V, Rumsfeld J, Sorlie P, Steinberger J, Thom T, Wasserthiel-Smoller S, Hong Y: Heart disease and stroke statistics-2007 update: a report from the American Heart Association Statistics Committee and Stroke Statistics Subcommittee. Circulation 2007, 115:e69-e171.

4. Mollazadeh R, Ostovan MA, Abdi Ardekani AR: Right cardiac thrombus in transit among patients with pulmonary thromboemboli. Clin Cardiol 2009, e27-e31,

5. Cracowski JL, Tremel F, Baguet JP, Mallion JM: Thrombolysis of mobile right atrial thrombi following severe pulmonary embolism. Clin Cardiol 1999, 22:151-154.

6. Richardson P, McKenna W, Bristow M, Maisch B, Mautner B, O'Connell J, Olsen E, Thiene G, Goodwin J, Gyarfas I, Martin I, Nordet P: Report of the 1995 World Health Organization/International Society and Federation of Cardiology Task Force on the Definition and Classification of cardiomyopathies. Circulation 1996, 93:841-842.

7. Harris KM, Spirito P, Maron MS, Zenovich AG, Formisano F, Lesser JR, Mackey-Bojack S, Manning WJ, Udelson JE, Maron BJ: Prevalence, clinical profile, and significance of left ventricular remodeling in the endstage phase of hypertrophic cardiomyopathy. Circulation 2006, 114:216-225.

8. Torbicki A, Galie N, Covezzoli A, Rossi E, De Rosa M, Goldhaber SZ: Right heart thrombi in pulmonary embolism: results from the International Cooperative Pulmonary Embolism Registry. I Am Coll Cardiol 2003, 41:2245-2251. 
9. Casazza F, Bongarzoni A, Centonze F, Morpurgo M: Prevalence and prognostic significance of right-sided cardiac mobile thrombi in acute massive pulmonary embolism. Am J Cardiol 1997, 79:1433-1435.

10. Lokhandwala J, Liu Z, Jundi M, Loyd A, Strong M, Vannan M: Threedimensional echocardiography of intracardiac masses. Echocardiography 2004, 21:159-163.

11. Lewis JF, Webber JD, Sutton LL, Chesoni S, Curry CL: Discordance in degree of right and left ventricular dilatation in patients with dilated cardiomyopathy: recognition and clinical implications. J Am Coll Cardiol 1993, 21:649-654.

12. Jenkins C, Bricknell K, Hanekom L, Marwick TH: Reproducibility and accuracy of echocardiographic measurements of left ventricular parameters using real-time three-dimensional echocardiography. J Am Coll Cardiol 2004, 44:878-886.

doi:10.1186/1476-7120-9-12

Cite this article as: Bai et al:: Assessment right atrial thrombus by realtime three dimensional transthoracic echocardiography in patient with dilated cardiomyopathy. Cardiovascular Ultrasound 2011 9:12.

\section{Submit your next manuscript to BioMed Central} and take full advantage of:

- Convenient online submission

- Thorough peer review

- No space constraints or color figure charges

- Immediate publication on acceptance

- Inclusion in PubMed, CAS, Scopus and Google Scholar

- Research which is freely available for redistribution

Submit your manuscript at www.biomedcentral.com/submit 